implied in the text is that of maximum output with minimum waste.

The facts contained in this book make it historically useful to many kinds of readers. It would be of particular interest to industrial economists and sociologists. It could be of use to the 'technologistadministrator' in upholding his long-term budget proposals in discussions with 'political-economic' planners.

G. A. RaNDELI

\section{TWELVE HUNDRED YEARS OF ADULT EDUCATION}

A History of Adult Education in Great Britain By Dr. Thomas Kelly. Pp. xii +352 . (Liverpool: The University Press, 1962.) 42s. net.

$\mathrm{D}$ R. KELLY has provided the first comprehensive history of adult education in Great Britain. A History of Adult Education, by J. W. Hudson, was published as long ago as 1851 , but it was concerned mainly with the adult schools and mechanics' institutes of the early nineteenth century. Dr. Kelly covers the period from the Middle Ages to 1939, with a last brief look at post-war changes and problems.

One fact that emerges very clearly is the consider. able effect the growth of science has had on adult education. From the Anglo-Saxon period until the seventeenth century adult education was mainly a function of religious institutions and movements. The course of development was from the instruction provided by the parish priest in pre-Reformation times to the preaching and Bible study of the Puritan lecturers. The first cause of the appearance of secular adult education was the geographical discoveries of the sixteenth century, which, through the stimulus they gave to the study of navigation, caused classes in mathematies and astronomy to be offered to adults. By the eighteenth century, in Dr. Kelly's words, "Public lectures on science became so widespread that a detailed record is impossible". Later the drive to spread scientific knowledge proved a major influence in two nineteenth-century developments, the foundation of mechanics' institutes and the beginning of university extension. In what are now accepted as the first university extension lectures in 1867, James Stuart insisted on taking the history of science as his subject, and in 1890-91 courses in natural science constituted more than one-third of the 457 courses provided by the universities of Oxford, Cambridge and London.

Dr. Kelly's book is not a narrowly conceived history of adult education but a contribution, from a particular point of view, to the history of British culture. He casts his net wide to show the general social, cultural and educational background against which developments in adult education took place. Readers with special knowledge of certain aspects of adult education will notice the broad generalizations and omissions inevitable in a survey of such a long period of history. They should also notice, however, the evidence of much painstaking research into obscure aspects of British educational history, for example, the extent of illiteracy in the early nine. teenth century and the contribution made to national education by the night schools of the early Victorian period. It seems likely that Dr. Kelly's book will stand alone in its particular field for a long time.

\section{COMPARATIVE ANATOMY AND TAXONOMY OF THE PRIMATES}

\section{Primates}

Comparative Anatomy and Taxonomy. By W. C Osman Hill. Vol. 5: Cebidae, Part B. Pp. xxi+ $537+31$ plates. (Edinburgh: At the University Press. Distributed by Thomas Nelson and Sons, Ltd., 1962.) 189s. net.

T HIS volume covers the sub-families Alouattinae and Atelinae and brings Dr. Osman Hill's work on primate anatomy to a stage of having treated all the prosimians and New World monkeys. The monograph follows a pattern now familiar to readers of its predecessors: a short historical introduction lead. ing to summary accounts of general and external features and followed by more detailed descriptions of individual anatomical systems. Sections dealing with behaviour, development and reproduction then lead to accounts of the geographical distribution and detailed taxonomy of each genus and, in the case of the Alouattinae, of the fossil genus Homunculus.

In contrast to earlier volumes where lack of detailed information necessitated the frequent use of descriptions compounded from several genera, the data have been sufficient for this general descriptive pattern to be followed for each genus, extensive gaps in the literature for the rare group Brachyteles being, so far as possible, filled by original observations of a specimen that became available when the book was in preparation. The result is a more balanced overall account than was possible in earlier volumes.

But within sub-sections, there is still an unevenness imposed, one can infer, by the still enormous gaps in knowledge-for example, whereas the space allotted in standard texts of human anatomy to descriptions of the external genitalia is about onefortieth of that accorded to the central nervous system, in Dr. Osman Hill's monograph the two, as in earlier volumes, rate equally. Again, in the descriptive sections, even when sufficient data are available, considerations of space have prohibited the inclusion of accounts of the variability of each feature. In fact, short of consulting the copious references quoted in the text, it is usually impossible to determine how many observations have formed the basis for each statement-a criticism which often, although not always, also applies to the presentation in these volumes of Dr. Hill's original observations. Consequently, although workers in this field cannot fail to admire Dr. Hill's sustained enthusiasm that has resulted in the publication of five volumes of this work in less than ten years, their gratitude cannot but be tempered by the realization that such qualifications materially reduce the value of these monographs as a basis for more detailed studies of form and function in individual anatomical regions and systems.

The anatomical descriptions lead to the taxonomic sections and these-presented in a classical stylemake it only too clear that, at present, only a fraction of the topographical material is sufficiently well known to enable the extent to which different characters vary between species and sub-species to be defined. But differences in many features are well established between higher taxonomic groups, and a critical reader leaves the volume with the impression that a selective treatment of these would have provided a more immediate contribution to primate biology. 